\title{
Prolonged acute diarrhea in adults: Decades of observation from epidemiological perspective in urban Bangladesh
}

\author{
Sumon Kumar Das ${ }^{1}$, Mohammod Jobayer Chisti ${ }^{1}$, Shahnawaz Ahmed ${ }^{1}$, Mohammad Abdul Malek ${ }^{1}$, \\ Fahmida Dil Farzana ${ }^{1}$, Farzana Ferdous ${ }^{1}$, Jonathan Latham ${ }^{2}$, Abu Syed Golam Faruque ${ }^{1^{*}}$ \\ ${ }^{1}$ Centre for Nutrition and Food Security (CNFS), International Centre for Diarrhoeal Disease Research, Bangladesh (icddr,b), Dhaka, \\ Bangladesh \\ ${ }^{2}$ London School of Hygiene and Tropical Medicine, London, UK \\ Email: " ${ }^{\prime}$ faruque@icddrb.org, sumon@,icddrb.org, chisti@,icddrb.org, shahnawz@icddrb.org, mamalek@icddrb.org, \\ fahmidaf@icddrb.org, farzanaf@icddrb.org, jonathan.r.latham@gmail.com
}

Received 5 May 2013; revised 5 June 2013; accepted 20 June 2013

Copyright (C) 2013 Sumon Kumar Das et al. This is an open access article distributed under the Creative Commons Attribution License, which permits unrestricted use, distribution, and reproduction in any medium, provided the original work is properly cited.

\begin{abstract}
The study aimed to determine the epidemiological, clinical characteristics, and etiology of adults aged $\geq 20$ years presented with prolonged acute diarrhea ( $\geq 7$ days). A total of 18,210 adults aged $\geq 20$ years were enrolled in the Diarrheal Disease Surveillance System of icddr,b between 1993-2012 and included into the analysis. Of these, 17,631 (97\%) had duration of diarrhea $\leq 6$ days, $418(2 \%)$ diarrhea presented with a duration of $7-13$ days and rest $161(1 \%)$ had history of diarrhea $\geq 14$ days. A higher proportion of adult individuals who had duration of diarrhea $\geq 14$ days $(70 \%$ vs. $56 \% ; p<0.001)$ and $7-13$ days $(62 \%$ vs. $56 \% ; p=0.006)$ compared to those $\leq 6$ days were male. At least $73 \%$ of all patients used oral rehydration solution; but proportion was lower among prolonged acute diarrhea groups. Use of antimicrobials was higher among those with duration 7 - 13 days $(81 \%)$ and $\geq 14$ days (81\%). Diarrhea lasting $\geq 14$ days, $47 \%$ were suffering from chronic energy deficiency and $30 \%$ had history of smoking. Individuals with diarrhea $\geq 7$ days less frequently presented with vomiting, watery stool, frequency of stool $>10$ times/24 hours, drowsy or lethargy, fast breathing, some or severe dehydration, received intravenous saline for initial corrections of dehydration and stayed for longer duration in hospital ( $\geq 24$ hours) but more often presented with abdominal pain. Stool microscopic examination showed less frequent presence of red blood cells $(36 \%$ vs. $44 \% ; p=0.043)$ and fecal leucocytes $(50 \%$ vs. $59 \%$; $p=0.029)$ among individuals with diarrhea $\geq 14$ days compared to those with $\leq 6$ days. None was infected with Vibrio cholerae ( $\geq 14$ days) (3\% for 7 - 13 days);
\end{abstract}

"Corresponding author. however, isolation rate of Aeromonas was higher among adults with duration for $\geq 14$ days $(11 \%)$. Only $15 \%$ with $\geq 14$ days were positive for Shigella contrary to $19 \%$ (7 - 13 days) and $56 \%$ ( $\leq 6$ days). Differences in sociodemographic, clinical presentation and etiology varied with duration of diarrhea among adults.

Keywords: Adult; Bangladesh; Diarrhea; Prolonged Acute Diarrhea

\section{INTRODUCTION}

Gastroenteritis due to various enteropathogens is not only a global burden among children but also among adults [1-3]. A recent study estimated diarrheal disease morbidity rates among adults in the South East Asian region to be 29.9 episodes/100 person-years compared to 88.4 episodes/100 person-years in older children in the Eastern Mediterranean region [4]. Although, mortality decreased over the last few decades among children, it remains consistent for adults [4].

Increasing age resulting in functional disorders of the gastrointestinal system often affects bowel habits including passage of loose stool and diarrhea [5,6]. Infection with enteropathogens, in addition to compromised immunity and physiological state of the intestine often results in prolonged acute diarrhea and also responsible for chronic sufferings $[5,6]$. Several studies have already documented different patho-physiological conditions regarding prolonged acute diarrhea as well as chronic diarrhea including hormonal imbalances as well as etiopathogens [5]. Prolonged acute diarrhea among adults is not only a chronic suffering for the patient but also a burden for the family and for the nation too [4,7]. However, there is limited information on prolonged acute diarrhea with regard 
to socio-demographic characteristics, clinical features, and its etiology in developing countries like Bangladesh.

The International Centre for Diarrhoeal Disease Research, Bangladesh (icddr,b) maintains around the clock Diarrheal Disease Surveillance System (DDSS) in urban Dhaka, the capital city which has been active since 1979 [8]. The analysis was undertaken to help address the knowledge gap, with the ultimate aim to determine the epidemiological and clinical characteristics and etiology of diarrhea among adults who presented with prolonged acute diarrhea.

\section{MATERIALS AND METHODS}

\subsection{Study Site, Population, and Source of Data}

Established in 1962, the Dhaka Hospital of icddr,b is located in Dhaka, the capital city of Bangladesh. The hospital provides care and treatment to people with diarrheal diseases, who mostly come from urban and periurban Dhaka. During the last 20 years, the hospital has provided cost free care and treatment to over 140,000 patients each year. The DDSS has been established in 1979 , which systematically sampled patients $-4 \%$ of all patients from 1979 through 1995, followed by $2 \%$ of all the patients since 1996 . The DDSS currently collects information on clinical, epidemiological and demographic characteristics, feeding practices particularly of infants and young children, and fluid and drug therapy received at homes of every $50^{\text {th }}$ patient, irrespective of age, sex, disease severity or socioeconomic status by administering a structured questionnaire.

\subsection{Sample Frame}

We categorized the adults aged 20 years and above into three groups according to the duration of their diarrhea before coming to the hospital. These classifications are: $\leq 6$ days (acute diarrhea), 7 to 13 days (prolonged acute diarrhea) and $\geq 14$ days (prolonged diarrhea). We followed their epidemiological identities such as sociodemographic and host characteristics, clinical course of the disease and etiology of diarrhea. Relevant information was extracted from the electronic database of the DDSS for the period 1993 to 2012 .

\subsection{Definition}

Diarrhea was defined as passage of three or more number of abnormally loose or watery stools in the preceding 24 hours. An individual aged 20 years and above was considered as adult. Adults who had a history of diarrhea 7 days and above before coming to the hospital were defined as prolonged acute diarrhea [9,10]. Fever was defined as axillary temperature more than $37.8^{\circ} \mathrm{C}$. Chronic energy deficiency was defined as individuals with BMI less than 18.5 and individuals with $\mathrm{BMI} \geq 25.0$ was considered as overweight and obese.

\subsection{Specimen Collection and Laboratory Procedures}

A single, fresh, stool specimen (at least $3.0 \mathrm{ml}$ or grams) was collected from each of the patients and immediately sent to the Clinical Laboratory for detection of Shigella [11], Vibrio cholerae [12,13], Campylobacter spp. [11], Aeromonas spp. [11], Salmonella [11], Giardia lamblia [14], Entamoeba histolytica [15], and rotavirus [16] following standard laboratory methodology. A stool microscopic examination was also performed in the same laboratory following standard procedure.

\subsection{Data Analysis}

Data analyses were done using Statistical Package for Social Sciences (SPSS) Windows (Version 15.2; Chicago, IL) and Epi Info (Version 6.0, USD, Stone Mountain, GA). For categorical variables, differences in the proportions were compared by Chi-square test and a probability of $<0.05$ was considered as statistically significant. Strength of association was determined by estimating odds ratio (OR) and its 95\% confidence interval (CI). Wealth index was measured by using information on household assets by computing principal component analysis. A weight was attached to each item from the first principal component. The households were classified into socio economic status (SES) quintiles based on the wealth index: quintile 1 (poor), 2 (lower middle), 3 (middle), 4 (upper middle), and 5 (rich). In the analysis, duration of diarrhea was categorized into 3 stratums such as: 1) $\leq 6$ days; 2) 7 - 13 days; and 3) $\geq 14$ days.

\subsection{Ethical Consideration}

The DDSS was approved by the RRC (Research Review Committee) and ERC (Ethical Review Committee) of icddr,b. Patients were enrolled and their stool specimens were collected for various laboratory tests only after they/ their parents (in case of minors) provided a verbal consent.

\section{RESULTS}

A total of 18,210 adults aged 20 years and above were enrolled in the DDSS. Of them, 17,631 (97\%) had a duration of diarrhea $\leq 6$ days (mean age; 37 years), 418 (2\%) had diarrhea lasting for 7 to 13 days (mean age; 41 years), and the remainder $161(1 \%)$ had history of diarrhea for $\geq 14$ days (mean age; 42 years).

A higher proportion of individuals with duration of diarrhea 7 - 13 days and $\geq 14$ days were male compared to those adults with history of diarrhea $\leq 6$ days. At least $73 \%$ of all adults used oral rehydration solution before 
coming to the hospital and proportion was lower among prolonged acute diarrhea group (Table 1). However, individuals with duration of diarrhea 7 days and above received more antimicrobials prior to hospital visit compared to adults with acute onset ( $\leq 6$ days). A significantly higher proportion of adults with diarrhea $\geq 14$ days suffered from chronic energy deficiency and had history of smoking compared to adults with diarrhea with duration of $\leq 6$ days. Other indicators like use of unboiled drinking water, sanitary toilet, family size, and proportion of overweight and obesity were not associated with duration of diarrhea (Table 1).

Adult individuals with prolonged acute diarrhea $(\geq 7$ days) presented with less vomiting, watery stool, less often had frequency of stool $>10$ times/day, not drowsy or lethargic or had fast breathing, had less often some or severe dehydration, less frequently received intravenous saline for initial correction of dehydration and did not stay longer in the hospital ( $\geq 24$ hours) compared to adults with acute diarrhea ( $\leq 6$ days). However, abdominal pain was more frequently reported by the adult patients with prolonged acute diarrhea (Table 2). Microscopic stool examination showed presence of red blood cells (RBC) and fecal leucocytes less commonly among prolonged acute diarrhea ( $\geq 14$ days) compared to acute diarrhea patients ( $\leq 6$ days) (Table 2 ).

Individuals with shorter duration of diarrhea ( $\leq 6$ days) were significantly more frequently infected with Vibrio cholerae and Shigella compared to adults with prolonged acute diarrhea. However, the isolation rate of Aeromonas was greater among adults with history of diarrhea $\geq 14$ days (Table 3). Other pathogens causing gastroenteritis such as Salmonella, Campylobacter, Aeromonas, Entamoeba histolytica, Giardia and rotavirus were equally distributed irrespective of duration of diarrhea (Table 3).

\section{DISCUSSION}

None of the adults with prolonged acute diarrhea attending the hospital triage with history of diarrhea for 14 days and more was infected with Vibrio cholerae. Clinical characteristics revealed that adult individuals with shorter duration of diarrhea presented with acute manifestations compared to those with prolonged duration which were detected to have often presence of this bacteria $[17,18]$. It is well documented that Vibrio cholerae infection is not only considered an acute illness but is

Table 1. Socio-demographic characteristics among adults according to duration of diarrhea.

\begin{tabular}{|c|c|c|c|c|c|}
\hline Indicators & $\begin{array}{c}\geq 14 \text { days } \\
\mathrm{n}=161(\%)\end{array}$ & $\begin{array}{c}7-13 \text { days } \\
n=418(\%)\end{array}$ & $\begin{array}{c}\leq 6 \text { days } \\
\mathrm{n}=17,631(\%)\end{array}$ & OR $(95 \%$ CI $)$ p value ${ }^{a}$ & OR $(95 \%$ CI $)$ p value \\
\hline Age (mean \pm SD) & $42 \pm 17$ & $41 \pm 15$ & $36 \pm 14$ & $-4.64(-6.13,-3.15)<0.001$ & $-5.51(-7.76,-3.36)<0.001$ \\
\hline Male sex & $113(70)$ & $261(62)$ & $9815(56)$ & $1.87(1.32,2.67)<0.001$ & $1.32(1.08,1.63) 0.006$ \\
\hline Use ORS prior to hospital & $117(73)$ & $334(80)$ & $15722(89)$ & $0.32(0.22,0.47)<0.001$ & $0.48(0.38,0.62)<0.001$ \\
\hline Use sanitary toilet & $4(3)$ & $14(3)$ & $454(3)$ & $0.96(0.30,2.71) 0.859$ & $1.31(0.73,2.30) 0.407$ \\
\hline $\begin{array}{l}\text { Use un-boiled } \\
\text { drinking water }\end{array}$ & $133(83)$ & $320(77)$ & $13578(77)$ & $1.42(0.93,2.18) 0.113$ & $0.97(0.77,1.23) 0.865$ \\
\hline Family size $(>5)$ & $58(36)$ & $177(42)$ & $6808(39)$ & $0.90(0.64,1.25) 0.554$ & $1.17(0.95,1.43) 0.135$ \\
\hline Poorest & $43(28)$ & $110(28)$ & $3339(21)$ & $1.47(1.02,2.12) 0.039$ & $1.48(1.18,1.86)<0.001$ \\
\hline Lower middle & $32(21)$ & $63(16)$ & $3090(19)$ & $1.10(90.73,1.65) 0.706$ & $0.80(0.60,1.06) 0.126$ \\
\hline Middle & $25(16)$ & 75 (19) & $3970(24)$ & $0.59(0.38,0.92) 0.019$ & $0.72(0.55,0.93) 0.012$ \\
\hline Upper middle & $20(13)$ & $69(17)$ & $3122(19)$ & $0.62(0.38,1.01) 0.056$ & $0.88(0.67,1.16) 0.386$ \\
\hline Richest & $36(23)$ & $81(20)$ & $2743(17)$ & $1.48(1.00,2.18) 0.051$ & $1.26(0.98,1.62) 0.078$ \\
\hline Smoking habit & $49(30)$ & $98(23)$ & $3910(22)$ & $1.54(1.08,2.18) 0.016$ & $1.07(0.85,1.36) 0.577$ \\
\hline $\begin{array}{l}\text { Chronic Energy Deficiency } \\
(\mathrm{BMI}<18.5)\end{array}$ & $70(47)$ & $155(40)$ & $6151(38)$ & $1.46(1.05,2.05) 0.025$ & $1.09(0.88,1.34) 0.445$ \\
\hline $\begin{array}{l}\text { Overweight and obese } \\
\quad(\mathrm{BMI} \geq 25.0)\end{array}$ & $16(11)$ & $44(11)$ & $1428(9)$ & $1.25(0.72,2.16) 0.480$ & $1.33(0.95,1.84) 0.099$ \\
\hline
\end{tabular}

${ }^{\mathrm{a}}$ Comparison between individuals with duration of diarrhea $\leq 6$ days and $\geq 14$ days; ${ }^{\mathrm{b}}$ Comparison between individuals with duration of diarrhea $\leq 6$ days and 7 13 days. 
Table 2. Clinical characteristics and stool microscopic examination among adults according to duration of diarrhea.

\begin{tabular}{|c|c|c|c|c|c|}
\hline Indicators & $\begin{array}{c}\geq 14 \text { days } \\
\mathrm{n}=161(\%)\end{array}$ & $\begin{array}{c}7 \text { - } 13 \text { days } \\
n=418(\%)\end{array}$ & $\begin{array}{c}\leq 6 \text { days } \\
\mathrm{n}=17,631(\%)\end{array}$ & OR $(95 \%$ CI $)$ p value ${ }^{a}$ & OR $(95 \%$ CI) p value \\
\hline Vomiting & $25(16)$ & $129(31)$ & $13806(78)$ & $0.05(0.03,0.08)<0.001$ & $0.12(0.10,0.15)<0.001$ \\
\hline Watery stool & $49(30)$ & $255(61)$ & $16720(95)$ & $0.02(0.02,0.03)<0.001$ & $0.09(0.07,0.11)<0.001$ \\
\hline Purging $>10$ times 24 hours & $42(26)$ & $175(42)$ & $9850(56)$ & $0.28(0.19,0.40)<0.001$ & $0.57(0.47,0.70)<0.001$ \\
\hline Drowsy or Lethargic & $30(19)$ & $150(36)$ & $13943(79)$ & $0.06(0.04,0.09)<0.001$ & $0.15(0.12,0.18)<0.001$ \\
\hline Fast breathing & $6(4)$ & $37(9)$ & $7948(45)$ & $0.05(0.02,0.11)<0.001$ & $0.12(0.08,0.16)<0.001$ \\
\hline Some or severe dehydration & $28(17)$ & $154(37)$ & $14280(81)$ & $0.05(0.03,0.08)<0.001$ & $0.14(0.11,0.17)<0.001$ \\
\hline Received Intravenous saline & $8(5)$ & $51(12)$ & $9731(56)$ & $0.04(0.02,0.09)<0.001$ & $0.11(0.08,0.15)<0.001$ \\
\hline Fever $\left(>37.8^{\circ} \mathrm{C}\right)$ & $5(3)$ & $13(3)$ & $580(3)$ & $0.94(0.34,2.39) 0.927$ & $0.94(0.52,1.69) 0.948$ \\
\hline Abdominal pain & $115(71)$ & $321(77)$ & $10956(62)$ & $1.52(1.07,2.18) 0.019$ & $2.02(1.59,2.55)<0.001$ \\
\hline $\begin{array}{l}\text { Duration of stay in the } \\
\text { hospital ( } \geq 24 \text { hours) }\end{array}$ & $25(16)$ & $60(15)$ & $3926(23)$ & $0.62(0.40,0.97) 0.037$ & $0.58(0.44,0.77)<0.001$ \\
\hline Red blood cells $(1->50)$ & $54(36)$ & $171(43)$ & $7515(44)$ & $0.70(0.49,0.99) 0.043$ & $0.96(0.78,1.18) 0.742$ \\
\hline Feacal leucocytes $(11->50)$ & $76(50)$ & $215(54)$ & $10084(59)$ & $0.69(0.50,0.97) 0.029$ & $0.82(0.67,1.01) 0.062$ \\
\hline Macrophage $(1-10)$ & $47(31)$ & $143(36)$ & $5810(34)$ & $0.87(0.60,1.24) 0.469$ & $1.10(0.89,1.35) 0.421$ \\
\hline
\end{tabular}

${ }^{a}$ Comparison between individuals with duration of diarrhea $\leq 6$ days and $\geq 14$ days; ${ }^{b}$ Comparison between individuals with duration of diarrhea $\leq 6$ days and 7 13 days.

Table 3. Distribution of pathogens among adults according to duration of diarrhea.

\begin{tabular}{|c|c|c|c|c|c|}
\hline Pathogens & $\begin{array}{c}\geq 14 \text { days } \\
n=161(\%)\end{array}$ & $\begin{array}{c}7-13 \text { days } \\
n=418(\%)\end{array}$ & $\begin{array}{c}\leq 6 \text { days } \\
\mathrm{n}=17,631(\%)\end{array}$ & OR $(95 \%$ CI) p value & OR $(95 \%$ CI $)$ p value ${ }^{b}$ \\
\hline Vibrio cholerae & $0(0)$ & $13(3)$ & $4344(25)$ & $0.00(0.00,0.09)<0.001$ & $0.10(0.05,0.17)<0.001$ \\
\hline Shigella & $25(15)$ & $81(19)$ & $986(56)$ & $3.10(1.97,4.86)<0.001$ & $4.06(3.13,5.25)<0.001$ \\
\hline Salmonella & $4(3)$ & $14(3)$ & $363(2)$ & $1.21(0.38,3.41) 0.920$ & $1.65(0.92,0.92) 0.099$ \\
\hline Rotavirus & $3(2)$ & $3(1)$ & $667(4)$ & $0.49(0.13,1.59) 0.302$ & $0.18(0.05,0.59) 0.002$ \\
\hline Campylobacter & $4(3)$ & $20(5)$ & $812(5)$ & $0.53(0.17,1.48) 0.275$ & $1.04(0.64,1.67) 0.956$ \\
\hline Aeromonas & $17(11)$ & $42(10)$ & $1181(7)$ & $1.64(0.96,2.79) 0.073$ & $1.56(1.11,2.17) 0.009$ \\
\hline Entamoeba histolytica & $5(3)$ & $14(4)$ & $292(2)$ & $1.95(0.70,4.97) 0.242$ & $2.10(1.17,3.71) 0.011$ \\
\hline Giardia & $2(1)$ & $2(1)$ & $373(3)$ & $0.60(0.10,2.46) 0.657$ & $0.23(0.04,0.92) 0.034$ \\
\hline Mixed infection & $15(9)$ & $44(11)$ & $2055(12)$ & $0.78(0.44,1.36) 0.425$ & $0.89(0.64,1.24) 0.526$ \\
\hline No pathogen detected & $50(31)$ & $156(37)$ & $8044(46)$ & $0.54(0.38,0.76)<0.001$ & $0.71(0.58,0.87)<0.001$ \\
\hline
\end{tabular}

${ }^{\mathrm{a}}$ Comparison between individuals with duration of diarrhea $\leq 6$ days and $\geq 14$ days; ${ }^{\mathrm{b}}$ Comparison between individuals with duration of diarrhea $\leq 6$ days and 7 13 days.

also widely responsible for epidemics [19]. Vibrio cholerae infection is characterized with acute onset with profuse loss of water and electrolytes often resulting in severe dehydration, which requires intravenous saline for correction. If untreated, cholera has a high mortality rate [20]. On the other hand, Shigella which causes dysentery is less frequently reported among adults with history of diarrhea for 7 to 13 days and 14 days and more. Only $15 \%$ adults with diarrhea for 14 days or more were found to be infected with Shigella. Due to the invasive nature of the pathogen, it disrupts intestinal epithelium and often presents with acute features of bloody mucoid stools with abdominal cramp, fever, and straining [21,22]. Comparatively, non-frequent presence of red blood cells and fecal leucocytes in stool microscopic examination among prolonged acute diarrhea groups were also found compared to acute onset.

Although the isolation rate of Shigella was relatively low among adults with prolonged acute diarrhea, a higher proportion complained of abdominal pain [20]. It 
might contradict the disease process, but those who presented with prolonged acute diarrhea might have other chronic gastrointestinal disorders such as inflammatory bowel disease (IBD) presented either as Crohn's disease or as ulcerative colitis [23]. Both might have chronic history of diarrhea with abdominal pain and weight loss [23]. This might be explained by higher proportion of males presenting with prolonged acute diarrhea; moreover, dietary practices (high protein, sodium and sugar consumption) and behavioral factors (smoking) with socio-cultural norms would be the other factors for such over reporting. Moreover, mean age of individuals with prolonged acute diarrhea (42 \pm 17 years) also favor with having chronic sufferings [24].

Significantly higher proportions of adults with prolonged acute diarrhea were smokers, the vast majority of which were males. This could also explain preponderance of the problem among males. Cigarettes contain nicotine that weakens protective factors such as gastric mucosal blood flow, mucosal restitution, epidermal growth factor, prostaglandin, glutathione and aggravated gastric acid secretion, increased infection with Helicobacter pylori, higher pepsinogen and vasopressin secretion all together alter gastrointestinal function resulting in nausea, anorexia and diarrhea [25-27]. This observation was supported by low BMI or higher rate of chronic energy deficiency among individuals with diarrhea lasting for 14 days and more. Chronic loss of water and electrolytes with loss of appetite resulting in reduced intake and impaired absorption would be the underlying predictors of current observation.

Most interestingly however was the presence of Aeromonas infection among adults with prolonged acute diarrhea ( $\geq 14$ days). Aeromonas is usually considered to be a self-limiting pathogen [28]. It is difficult to explain the higher isolation rate of Aeromonas among adults. Hypothetical explanations could be, individuals might have infected with pathogens that cause acute infection but once the disease progressed different enteropathogens might have sequentially predominated to worsen the duration of the illness as reported by Baqui A.H. et al. (1992) among under-5 children who developed persistent diarrhea [29].

Use of antimicrobials at home would be another challenge. Adult individuals with duration of diarrhea for 7 days and more might attempt to manage illness at home with oral rehydration solution and/or antimicrobials. On the other hand, use of antimicrobials might cause disease due to Clostridium difficile, responsible for chronic diarrhea among adults and elderly [30]. However, in the present study we did not target to isolate this pathogen.

\section{LIMITATION}

There are several limitations of the observations. Firstly, lack of information about repeated onset of prolonged acute diarrhea. Either it was an episode of prolonged acute diarrhea or it might be a recurrent episode of prolonged acute diarrhea as part of chronic sufferings such as, irritable bowel syndrome or ulcerative colitis or Crohn's disease. Secondly, isolation of limited number of common pathogens those are causing gastroenteritis. There are other pathogens such as Clostridium difficiles, E. coli, norovirus or Cryptosporidium responsible for prolonged acute or chronic diarrhea [31]. Thirdly, lack of information on immune status that often gets compromised with increasing age. Other than that, dietary habits and other endocrine disorders like hyperthyroidism or Addison disease or diabetic mellitus might have significant role in chronic sufferings. However, unbiased systematic enrollment with large sample size and high quality laboratory performance were the strengths of the study.

\section{CONCLUSION}

Increases in life expectancy as a result of modernization of care seeking facilities might invite chronic health problems like prolonged acute diarrhea among adults. Differences in socio-demographic, clinical presentation and etiology signify its public health importance. There is a lack of a national monitoring system regarding the epidemiological investigations with documentation of chronic illnesses like chronic diarrhea. At the same time, indepth exploration or research should be implemented to address the knowledge gaps and continue the surveillance system to understand the changes in adult disease profiles of general population over the period.

\section{ACKNOWLEDGEMENTS}

Diarrheal Disease Surveillance System (DDSS) of icddr,b was supported for some of the study years by the Government of the People's Republic of Bangladesh under its IHP-HNPRP. icddr,b acknowledges with gratitude the commitment of the Government of the People's Republic of Bangladesh to the icddr, b's research efforts. icddr, b also gratefully acknowledges the following donors which provide unrestricted support to its research efforts: Australian Agency for International Development (AusAID), Government of the People's Republic of Bangladesh, Canadian International Development Agency (CIDA), Embassy of the Kingdom of the Netherlands (EKN), Swedish International Development Cooperation Agency (Sida), Swiss Agency for Development and Cooperation (SDC), and Department for International Development, UK (DFID).

\section{REFERENCES}

[1] Boschi-Pinto, C., Velebit, L. and Shibuya, K. (2008) Estimating child mortality due to diarrhoea in developing countries. Bull World Health Organ, 86, 710-717.

[2] Fischer Walker, C.L., Sack, D. and Black, R.E. (2010) Etiology of diarrhea in older children, adolescents and adults: A systematic review. PLoS Neglected Tropical Di- 
seases, 4, e768. doi:10.1371/journal.pntd.0000768

[3] Manatsathit, S., Dupont, H.L., Farthing, M., et al. (2002) Guideline for the management of acute diarrhea in adults. Journal of Gastroenterological Hepatology, 17, S54-S71.

[4] Walker, C.L. and Black, R.E. (2010) Diarrhoea morbidity and mortality in older children, adolescents, and adults. Epidemiology and Infection, 138, 1215-1226. doi:10.1017/S0950268810000592

[5] Juckett, G. and Trivedi, R. (2011) Evaluation of chronic diarrhea. American Family Physician, 84, 1119-1126.

[6] Lopman, B.A., Hall, A.J., Curns, A.T., et al. (2011) Increasing rates of gastroenteritis hospital discharges in US adults and the contribution of norovirus, 1996-2007. Clinical Infectious Diseases, 52, 466-474. doi:10.1093/cid/ciq163

[7] Lamberti, L.M., Fischer Walker, C.L. and Black, R.E. (2012) Systematic review of diarrhea duration and severity in children and adults in low- and middle-income countries. BMC Public Health, 12, 276.

[8] Das, S.K., Chisti, M.J., Huq, S., et al. (2013) Etiology of Diarrhea among Severely Malnourished Infants and Young Children: Observation of Urban-Rural Differences over One Decade in Bangladesh. Food and Nutrition Sciences, 4, 233-239. doi:10.4236/fns.2013.43031

[9] Schilling K.A. (2010) Characteristics and etiology of moderate-to-severe diarrhea of acute, prolonged acute, and persistent duration among children less than 5 years old in rural western Kenya, 2008-2010. Georgia State University.

[10] Bhutta, Z.A., Nelson, E.A., Lee, W.S., et al. (2008) Recent advances and evidence gaps in persistent diarrhea. Journal of Pediatric Gastroenterology and Nutrition, 47, 260-265. doi:10.1097/MPG.0b013e318181b334

[11] WHO (1987) Programme for control of diarrheal disease. In Manual for laboratory investigation of acute enteric infections. World Health Organization, Geneva.

[12] Qadri, F., Azim, T., Chowdhury, A., et al. (1994) Production, characterization, and application of monoclonal antibodies to Vibrio cholerae O139 synonym Bengal. Clinical and Diagnostic Laboratory Immunology, 1, 51-54.

[13] Rahman, M., Sack, D.A., Mahmood, S., et al. (1987) Rapid diagnosis of cholera by coagglutination test using 4-h fecal enrichment cultures. Journal of Clinical Microbiology, 25, 2204-2206.

[14] Haque, R., Mondal, D., Karim, A., et al. (2009) Prospective case-control study of the association between common enteric protozoal parasites and diarrhea in Bangladesh. Clinical Infectious Diseases, 48, 1191-1197. doi:10.1086/597580

[15] Haque, R., Neville, L.M., Hahn, P., et al. (1995) Rapid diagnosis of Entamoeba infection by using Entamoeba and Entamoeba histolytica stool antigen detection kits. Journal of Clinical Microbiology, 33, 2558-2561.

[16] Rahman, M., De Leener, K., Goegebuer, T., et al. (2003) Genetic characterization of a novel, naturally occurring recombinant human G6P[6] rotavirus. Journal of Clinical Microbiology, 41, 2088-2095. doi:10.1128/JCM.41.5.2088-2095.2003
[17] Weil, A.A., Khan, A.I., Chowdhury, F., et al. (2009) Clinical outcomes in household contacts of patients with cholera in Bangladesh. Clinical Infectious Diseases, 49, 1473-1479. doi:10.1086/644779

[18] Khan, A.I., Chowdhury, F., Harris, J.B., et al. (2010) Comparison of clinical features and immunological parameters of patients with dehydrating diarrhoea infected with Inaba or Ogawa serotypes of Vibrio cholerae O1. Scandinavian Journal of Infectious Diseases, 42, 48-56. doi:10.3109/00365540903289688

[19] Sigman, M. and Luchette, F.A. (2012) Cholera: Something old, something new. Surgical Infections (Larchmt), 13, 216-222. doi:10.1089/sur.2012.127

[20] Alam, N.H. and Ashraf, H. (2003) Treatment of infectious diarrhea in children. Paediatric Drugs, 5, 151-165.

[21] Echeita Sarrionandia, M.A., Leon, S.H. and Baamonde, C.S. (2011) Invasive gastroenteritis, anything new? Enfermedades Infecciosas y Microbiologia Clinica, 29, 55-60.

[22] Lai, S.W., Lin, H.C., Lin, C.C., et al. (2000) Clinical analysis of a dysentery outbreak in Taichung. Acta Paediatrica Taiwanica, 41, 18-21.

[23] Stein, J.R., Hartmann, F. and Dignass, A.U. (2010) Diagnosis and management of iron deficiency anemia in patients with IBD. Nature Reviews Gastroenterology \& Hepatology, 151.

[24] Hopman, W.M., Harrison, M.B., Coo, H., Friedberg, E., Buchanan, M. and VanDenKerkhof, E.G. (2009) Associations between chronic disease, age and physical and mental health status. Chronic Diseases in Canada, 29, 108116.

[25] Massarrat, S. (2008) Smoking and gut. Archives of Iranian Medicine, 11, 293-305.

[26] Thomas, G.A., Rhodes, J. and Ingram, J.R. (2005) Mechanisms of disease: nicotine-A review of its actions in the context of gastrointestinal disease. Nature Clinical Practice Gastroenterology \& Hepatology, 2, 536-544.

[27] Wu, W.K. and Cho, C.H. (2004) The pharmacological actions of nicotine on the gastrointestinal tract. Journal of Pharmacological Science, 94, 348-358. doi:10.1254/jphs.94.348

[28] Aeromonas detection: What does it mean? Water: Unregulated Contaminant Monitoring Program.

http://water.epa.gov/lawsregs/rulesregs/sdwa/ucmr/data_a eromonas.cfm

[29] Baqui, A.H., Sack, R.B., Black, R.E., et al. (1992) Enteropathogens associated with acute and persistent diarrhea in Bangladeshi children less than 5 years of age. The Journal of Infectious Diseases, 166, 792-796. doi:10.1093/infdis/166.4.792

[30] Osterholm, M.T., MacDonald, K.L., White, K.E., et al. (1986) An outbreak of a newly recognized chronic diarrhea syndrome associated with raw milk consumption. JAMA, 256, 484-490. doi:10.1001/jama.1986.03380040058029

[31] Pawlowski, S.W., Warren, C.A. and Guerrant, R. (2009) Diagnosis and treatment of acute or persistent diarrhea. Gastroenterology, 136, 1874-1886. doi:10.1053/j.gastro.2009.02.072 